\title{
Distribution of surface active substances in the Northern Adriatic Sea
}

\author{
Blaženka Gašparović*, Božena Ćosović \\ Center for Marine and Environmental Research, Ruđer Bošković Institute, POB 180, \\ HR-10002 Zagreb, Croatia
}

\begin{abstract}
Spatial distribution and seasonal variability of surfactant activity (SA) of seawater were studied in the Northern Adriatic Sea and compared to the temperature and salinity patterns in the two year period from February 1998 to January 2000, based on monthly surveys. Surface active substances were determined with alternating current voltammetry (in-phase mode) using o-nitrophenol as an electrochemical probe. A general characteristic of the SA seasonal variability for the Northern Adriatic is the sinusoidal change of SA within the period of one year; similar behaviour was observed for the seasonal variations of temperature. Maximum SA values appeared during the summer period while minimum SA values were measured in winter, during the period of well-mixed water layers and lower phytoplankton production. In May and October, the highest SA values were obtained in the upper seawater layer, which was ascribed to the influence of high inflow of nutrient rich Po River freshwater. Riverine inputs indirectly favour autochthonous production processes, which result in increased concentration of organic matter, particularly surface active substances.
\end{abstract}

Keywords: surfactant activity, o-nitrophenol probe, voltammetry, Northern Adriatic Sea 


\section{Introduction}

Organic matter $(\mathrm{OM})$ in the sea is a very complex mixture of substances with different physico-chemical properties. It originates from different sources, mainly from in-situ production (Lee and Wakeham, 1988) and to a lesser extent from the atmosphere and the land (Meyers-Schulte and Hedges, 1986). A large fraction of OM has surface active properties (Hunter and Liss, 1982). These surface active substances make up a very reactive part of the organic matter in the sea. According to their surface active properties such substances accumulate at marine interfaces (seawater-air, -living and nonliving particles and -sediment), influencing mass and energy transfer between the thus modified interfaces. Adsorbed films at the air-sea interface may influence air-sea exchanges considerably (Frew et al., 1990, Frew, 1997), which is particularly important in the problem of global warming. Owing to their different functional groups, surface active organic substances participate in different types of interactions, both in the water column and on the phase boundaries. The variability and reactivity of surface active substances (SAS) render their characterization important for understanding the main processes which controll the carbon cycling in the Northern Adriatic. Some information can be gained by examining the annual SAS cycle.

The Northern Adriatic Sea, biologically the most productive part of the Adriatic, is a shallow basin. It is characterised by limited circulation of sea water mass and is strongly influenced by the Po River discharge, which markedly increases its biological productivity over the oligotrophic features of the Mediterranean Sea and of most of the Adriatic sea (Harding et al., 1999). The major sources of nutrients in this region are the Po River discharge which accounts for about $50 \%$ of the total nutrient load transported into the Northern Adriatic (Degobbis and Gilmartin, 1990), and winter overturn of regenerated 
nutrients from the bottom layer (Degobbis, 1990). The Po River mean concentrations of dissolved nutrients are $147 \mu \mathrm{M} \mathrm{N}, 4.6 \mu \mathrm{M}$ P and $120 \mu \mathrm{M} \mathrm{Si}$, respectively (Justić et al., 1995). Concentrations of nutrients in the Northern Adriatic ranged from values under detection limits to $78 \mu \mathrm{M}$ TIN, $1.1 \mu \mathrm{M}$ TP and $59 \mu \mathrm{M} \mathrm{SiO} 4$ in the period from 1966 to 1981 as reported by Gilmartin et al. (1990). It is also reported that nutrient concentrations in the period 1988-1990 remained approximately at the same level as those in the seventies (Degobbis, 1995). The loads of total organic carbon and nitrogen transported by the Po River were estimated to be $25.5 \times 10^{4}$ and $15.5 \times 10^{4}$ tons per year (Pettine et al., 1998). Long-term investigations (1989-1993) of DOC values in the Northern Adriatic Sea (Vojvodić and Ćosović, 1996) showed that DOC concentrations are in the range of 1.13 to $3.06 \mathrm{mg} \mathrm{C} \mathrm{dm}{ }^{-3}$. Dissolved organic carbon in the western part of the Northern Adriatic in 1995 showed no evident distribution trend in the water column (Giani et al., 1999). Concentrations of POC in this basin ranged from ca 75 to $1701 \mu \mathrm{g} \mathrm{dm}{ }^{-3}$ in the summer season. Surface concentrations of POC were two to three times those observed in the bottom layer (Gilmartin and Revelante, 1991), and two to five times higher in coastal stations near the Po River delta than in offshore stations (0.1-0.18 $\mathrm{mg} \mathrm{dm}^{-3}$ ) (Giani et al., 1999). The Po River mean concentrations of DOC and POC are 2.1 and $2.4 \mathrm{mg} \mathrm{C} \mathrm{dm}^{-3}$, respectively (Pettine et al., 1998). Surface active substances (SAS), which are part of the organic carbon, cover a wide range of values from 0.015 to $0.475 \mathrm{mg} \mathrm{dm}^{-3}$ expressed as equiv. Triton-X-100. SAS are found prevalently in the dissolved form (Vojvodić and Ćosović, 1996).

Evaluation of the concentration and characteristics of the SAS in marine samples is very conveniently performed using electrochemical methods. These methods provide information on all coexisting adsorbable substances that are involved in the adsorption on the surfaces in a competitive manner (Ćosović, 1990). There are several electrochemical 
techniques which are used for the determination of SAS in marine samples, such as phase sensitive alternating current voltammetry (Ćosović and Vojvodić, 1982; 1998), the method of the polarographic maximum (Žutić et al., 1981), the Kalousek commutator technique (Kozarac et al., 1976), and the use of the electrochemical probe (Kozarac et al., 1986; Gašparović and Ćosović, 1994). All these methods differ in the type of electrical excitation, measured response, time-scale and surface electrode charge. These facts result in their different specific sensitivity to various classes of surface-active molecules (Ćosović, 1985). Alternating current voltammetry has been shown to be a very convenient method for the characterization of organic substances, from hydrophilic polysaccharides and conditionally hydrophobic humic substances, to very hydrophobic fatty acids (Gašparović and Ćosović, 1994; Vojvodić et al., 1994). In this work organic matter has been characterized using o-nitrophenol as an electrochemical probe. This method is based on the fact that surface active organic matter, when adsorbed on the mercury electrode, influences the oxido-reduction processes of o-nitrophenol. This influence is indicated by different shifts in the peak potential, and by changes in the peak height and shape in the different layers. The shift of the o-nitrophenol peak potential in the presence of increasing concentrations of surface active substances is well correlated with the decrease of the capacity of the electric double layer during the adsorption of organic matter onto the electrode surface. The latter effects are at the basis of the SAS measurements in the phase sensitive alternating current voltammetry.

In this work we attempted to assess the seasonal variability of SAS and to elucidate the factors which influence the distribution of SAS in the Northern Adriatic Sea, and with special emphasis, the influence of Po River freshwater inputs. This paper describes the results of monthly monitoring of SAS along the transect from the Croatian coast to the Po River delta over a of two year period. The appearance of gelatinous macroaggregates, 
which occurred in this region with a higher frequency in the last decade than in the past (Degobbis et al., 1995), was not observed during this two year of investigation.

\section{Experimental}

\subsection{Study area and sampling}

Seasonal and spatial distributions of SAS were determined over a two-year cycle in the Northern Adriatic Sea, on the transect from the Po River mouth to Rovinj (Fig. 1). The stations along this transect were considered as representative for the Northern Adriatic (Gilmartin et al. 1990) and their basic hydrographic properties, nutrients and phytoplankton dynamics have been regularly surveyed since 1976 at intervals from monthly to seasonal.

In this study monthly sampling was performed during the period from February 1998 to January 2000. Samples were collected from the research vessel "Vila Velebita" at the 6 stations shown in Fig. 1 with 5-liter Niskin bottles. Samples were stored in dark glass bottles at $4{ }^{\circ} \mathrm{C}$ and measured, at room temperature, directly within $24 \mathrm{~h}$. Surface samples $(0.5 \mathrm{~m})$ were collected from all the stations while at station 101, under the direct influence of the Po River discharge, and station 107, which is rarely influenced by Po River waters, samples were taken at 5-6 different depths.

\subsection{Methods and materials}

Surface active substances were determined by phase-sensitive alternating current (a.c.) voltammetry by in-phase measurements using o-nitrophenol (ONP) as an electrochemical probe, as described in previous papers (Gašparović and Ćosović 1994, 
1995). All the measurements were performed using the EDT-ECP-100 Modular Research Polarograph, connected to the ECP-110 unit (EDT) and to a Hewlett-Packard 7045 A recorder. The frequency of a.c. voltage was $170 \mathrm{~Hz}$, and the p-p amplitude was $10 \mathrm{mV}$. Scan rate was $20 \mathrm{mV} \mathrm{s}^{-1}$. All the experiments were performed using a three-electrode system with a hanging mercury drop electrode (Metrohm, Switzerland). $\mathrm{An} \mathrm{Ag} / \mathrm{AgCl} / 3 \mathrm{M}$ $\mathrm{KCl}$ electrode was used as the reference electrode and a platinum wire as the auxiliary electrode. ONP $\left(10^{-4} \mathrm{M}\right)$ was added to the model solution or marine samples immediately before the voltammetric measurement. Seawater samples were measured without any previous treatment, except addition of ONP. Model solutions were $0.55 \mathrm{M} \mathrm{NaCl}$ and $2 \times 10^{-3}$ $\mathrm{M} \mathrm{NaHCO}$, at $\mathrm{pH}$ 8.4, simulating seawater conditions. Organic matter was accumulated on the mercury electrode by stirring the solution at the potential of $-0.35 \mathrm{~V}$ for $3 \mathrm{~min}$, before the potential scanning.

All the voltammetric measurements of ONP included one scan from the accumulation potential $(-0.35 \mathrm{~V})$ up to $-0.89 \mathrm{~V}$, which represents the main ONP peak. The reproducibility of electrochemical measurements was 8-10\%. All chemicals used were of reagent grade.

ONP has a voltammetric reduction peak at $-0.555 \mathrm{~V}$ under the $\mathrm{pH}$ conditions of seawater. In the presence of organic matter adsorbed onto the mercury electrode, the ONP peak potential is shifted toward more negative potentials, depending on the concentration and the hydrophobicity of adsorbed organic substances. Typical ac voltammograms of ONP obtained with different accumulation times for the Northern Adriatic seawater sample from the station 101 taken in August 1999 from 0.5 m depth, are presented in Fig. 2.

When using the ONP electrochemical probe, the SAS concentration (surfactant activity) of natural seawater samples is expressed as the equivalent concentration of the nonionic detergent Triton-X-100 (T-X-100), which gives the same ONP peak potential 
shift $(\Delta \mathrm{E})$ as the natural organic substances in the sample. The calibration curve for the dependence of ONP peak potential shift on T-X-100 concentration is presented in Fig. 3. All the results of peak potential shift for seawater samples and model solutions of T-X-100 were normalised to 0 min accumulation time and possible differences due to different $\mathrm{pH}$ were avoided.

Temperature was measured with a reversing thermometer and salinity with a Beckman RS 7C high precision bench salinometer.

\section{Results}

Oceanographic properties of the Northern Adriatic Sea exhibited high vertical and horizontal gradients, created primarily by the freshwater discharge of the Po River and the meteorological conditions.

The distributions of temperature and salinity over the study period are given for station 101 and station 107 in Fig 4.a and 4.b.

Temperature distribution shows a regular sinusoidal annual cycle. The temperature maximum shifted and decreased from August to October, depending on the water depth. This shift reflects a necessary time-lag due to surface-bottom heat transfer. A temperature minimum was observed in February.

The distribution of salinity exhibited strong seasonal fluctuations during the two year study, characterized by two large inputs of the Po River freshwater which occurred in May and in October (a less pronounced one). This was especially pronounced for the $0.5 \mathrm{~m}$ and $5 \mathrm{~m}$ depths and for station 101. The water column was generally well-mixed from November through February. 
Seasonal variations of the surfactant activity of OM for the station 101, which is under a direct influence of the Po River discharge are presented in Fig. 5. The results are given for surface waters $(0.5 \mathrm{~m}), 5 \mathrm{~m}, 10 \mathrm{~m}$, and $20 \mathrm{~m}$ depths, and for bottom waters $(30 \mathrm{~m})$.

Surfactant activity in the bottom layer ranged from 0.04 to $0.11 \mathrm{mg} / \mathrm{dm}^{-3}$ equiv. T-X100. The maximum was obtained in August while the minimum was observed in the winter period, December to February.

Surfactant activity of the surface layer varied from 0.04 to $0.16 \mathrm{mg} / \mathrm{dm}^{-3}$ equiv. T-X100. The lower values in the above range were observed in the winter period. The highest SA values were recorded in May and in October, for both years. The SA maximum shifted and decreased from May to August with increasing depth.

The seasonal variations of SA at the different depths of the station 107 are presented in Fig. 6. This station is only weakly influenced by the Po River waters, as shown by salinity values (Fig 4.b).

Surfactant activity in bottom waters $(30 \mathrm{~m}$ and $20 \mathrm{~m}$ ) had approximately similar values, between 0.032 and $0.11 \mathrm{mg} / \mathrm{dm}^{-3}$ equiv. T-X-100, during the two years of investigations. Upper water layers $(10 \mathrm{~m}, 5 \mathrm{~m}$ and $0.5 \mathrm{~m}$ depths $)$ had higher SA values compared to bottom waters. The SA values varied in the range from 0.035 to 0.126 , and from 0.035 to $0.133 \mathrm{mg} / \mathrm{dm}^{-3}$ equiv. T-X-100 at 10 and $5 \mathrm{~m}$ depths, respectively. The surface water layer had SA values in the range from 0.048 to $0.144 \mathrm{mg} / \mathrm{dm}^{-3}$ equiv. T-X-100.

Fig. 7 shows the changes in the surfactant activity measured in surface seawater samples $(0.5 \mathrm{~m})$, at different distances. Results are given for a few representative months in 1998 and 1999: December and February for winter, July and August for summer and April and May for the spring period which is characteruzed by high freshwater input. The results are also related to the temperature and salinity variations obtained in 1998 (Fig. 8) and 1999 (Fig. 9). 
In the winter period SA values were relatively uniformly distributed along the transect River Po-Rovinj. The same was the case with the temperature. Also, the salinity was high (37.7-38.2\%0), and uniformly distributed. The evaluated concentrations of SAS for this period ranged from 0.04 to $0.064 \mathrm{mg} / \mathrm{dm}^{-3}$ equiv. T-X-100.

Generally, SA for the spring period varies in the range from 0.045 to $0.17 \mathrm{mg} / \mathrm{dm}^{-3}$ equiv. T-X-100. A marked decrease of SA values was observed from the stations close to the Po River discharge to those close to the Croatian coast, especially in 1999. An opposite pattern was obtained for salinity, with low values recorded at the stations close to the Po River delta. Temperature values showed a similar, although less pronounced, trend as the SA values, with high values detected at low salinity.

The summer period, with high temperature and low freshwater inflow, was characterised by SA values lower than those in spring for the stations close to the Po River discharge. As a whole, SA values varied in the summer in a much narrower range (from 0.092 to $0.136 \mathrm{mg} / \mathrm{dm}^{-3}$ equiv. T-X-100) than in spring, and SDA values were on average 2.9 times higher than in the winter period.

\section{Discussion}

The SA distribution in the Northern Adriatic shows a sinusoidal pattern within a period of one year. A similar behaviour was observed for the seasonal variations of the temperature. The sinusoidal SAS and temperature variations are characterized by an amplitude that decreases with depth. The minimum SA value is recorded in winter, when the water column is completely mixed. SAS concentration start to increase in March, in coincidence with the spring bloom of diatoms, which usually occurs in the North Adriatic after snow melting (Revelante and Gilmartin, 1976b). The maximum SA is obtained in the 
summer period for the upper layers and shifts to a later period of the year for the deeper water layers.

Surface layers $(0-10 \mathrm{~m})$ differ from the deeper layers by pronounced jumps of SA in May and October, which paralleled decreasing peaks in salinity caused by high Po River freshwater inputs (Boicuort et al., 1999). These SA jumps are superimposed on the main sinusoidal change of SA during the year.

Since the data for temperature and surfactant activity, measured during the two year study period, exhibit apparent seasonal variations we have assumed a sinusoidal timedependence of the form:

$$
\mathrm{y}=\mathrm{y}_{0}+\mathrm{A} \sin (2 \pi \mathrm{x} / \omega+\delta)
$$

where $y_{0}$ represents the average value of surfactant activity or temperature, $\mathrm{A}$ is the amplitude of variations, $\omega$ is the frequency (12 months), $\mathrm{x}$ is the month of the year and $\delta$ is the phase shift.

The measured data were statisticaly analysed to infer correlation between relevant parameters $(\mathrm{T}, \mathrm{S})$ and SAS.

This statistical analysis showed that the correlation coefficient for the SAS temperature relationship decreases continuously and slowly from high values at the surface $(\mathrm{R} \approx 0,85)$, corresponding to a very significant t-test value at $99 \%$ confidence level, to about $\mathrm{R} \approx 0.5$ for bottom layers.

The influence of the Po River discharge on the concentration of SAS is followed through the decrease in salinity, and statisticaly analysed. The correlation coefficient for the SAS - salinity relationship is high and negative $(\mathrm{R}>-0.75)$ for surface waters and rapidly drops with depth reaching a nearly constant value of $R \approx-0.2$ for depth $\geq 10 \mathrm{~m}$. The statistical t-test of the correlation hypothesis for the SAS - salinity dependence gave a very high significance value (confidence level 99\%) for surface waters, while for depths $\geq 10 \mathrm{~m}$ 
it gave a non significant value even at the $95 \%$ confidence level. Hence, we conclude that the variations of SAS in surface water are correlated with fresh water inputs, as indicated by the observed coincidence of SAS peaks and salinity minimum values (compare Figs. 4 with Figs. 5 and 6, May and October)

The similar sinusoidal changes of the temperature and SA during the year indicate a strong connection of the SA distribution in the Northern Adriatic with the temperature, i.e. with seasonal variations of biological activity. Namely, a significant part of surfactant activity in the seawater column is found to be due to phytoplankton production ( Zutic et al., 1981). High jumps of SA values at station 101 coinciding with the period of low salinity (compare Fig. 4a and Fig. 5) point to the important influence of nutrient rich Po River freshwater inputs. The increased concentration of surface-active organic substances can be directly related to riverine discharges of organic matter and/or indirectly produced by autochtonous processes driven by the fertilizing effect of discharged nutrients. Since nutrients tend to remain in the less dense surface waters (Gilmartin et al., 1972) this effect is especially pronounced for surface waters.

It is important to notice that the SA maximum always occurs earlier in the year than the temperature maximum. For both stations, on average, the difference is from one to two months, and also increases with depth. Comparing the two stations it can be seen that this difference is a little bit more pronounced in the station 107.

Annual cycles and interannual variability of phytoplankton biomass and primary productivity in the Northern Adriatic are strongly driven by the Po River fresh water inflow and nutrient loading from river water discharge. There is a strong west to east gradient of chlorophyll- $a$ in surface waters, with the highest concentrations occurring toward the Italian coast (Revelante and Gilmartin, 1976a; Ahel and Terzić, 1998). 
Nanoplankton usually dominate the phytoplankton community in the Northern Adriatic. The blooms result from the increase in the microplankton component. Dinoflagellates dominate during the summer, while the rest of the year is dominated by diatoms (Revelante and Gilmartin, 1976a and b). Mozetič et al. (1998) found that smallsized cells (microflagellates, coccolithophores) dominate during periods of low chlorophyll- $a$ concentrations in the northernmost part of the Adriatic Sea. Seasonal and spatial patterns of chlorophyll- $a$ distribution show low concentrations during the summer period and enhanced concentrations in spring and autumn. The surface layer is the most variable part with respect to phytoplankton dynamics.

Changes in the surfactant activity of surface waters $(0.5 \mathrm{~m})$ along the transect from the Po River mouth to the Croatian coast showed a marked influence of Po River freshwater. While salinity was increasing from the Po River mouth to the Croatian coast, SA was decreasing. These changes were less pronounced for the represented months in the 1998 in comparison to 1999. Apart from the increased phytoplankton production stimulated by freshwater inputs of nutrients, another reason for the increased SAS concentrations in the Po River delta region might also be the direct discharge of biorefractory compounds (Pettine et al., 1999). Pettine et. al. (1998) found that DOC values in the Po River waters were generally slightly higher than those in coastal waters, except in June. They explained their findings by the high productivity that characterizes this coastal zone in the summer period. As low temperature and limited light intensity limit phytoplankton production during the winter, this was also reflected in a low surfactant activity in that period of the year. Generally, in the winter season surfactant activity was several times lower than in the summer period. 


\section{Conclusions}

The general characteristic of the SA distribution for the Northern Adriatic is a sinusoidal change of SA within the period of one year. The highest SA values, obtained in the surface layer, coincide with the spring and autumn pulses of nutrient enriched Po River freshwaters. The strongest impact of the Po River discharge on SA was observed for the station(s) which was(were) under its direct influence, as reflected in a significant decrease of salinity. This influence was decreasing in the direction of the eastern part of the Northern Adriatic.

The statistical analysis of experimental data confirms the hypothesis that the SAS quantity and its seasonal variations are related to the sine-like cycle of temperature and salinity variations. The correlation with salinity is more pronounced in the surface layer while temperature correlation is preserved (although decreasing with depth) through the whole column.

Our results suggest that the SA values in the Northern Adriatic are highly dependent on the phytoplankton community production, which in turn depends on temperature, sunlight irradiation and nutrients. Pronounced peaks of SA which are coincident with Po river inputs are superimposed on the basic sinusoidal variations of SA. These inputs are pointed out by significant drops in salinity. High inputs of nutrients by the Po River stimulate phytoplankton production, which is in turn reflected in the increased SAS concentration, particularly in the surface layer. In the winter, which is a period of low primary production due to low temperature and limited sunlight irradiation, the SA values were the lowest.

As the minimum and maximum values of DOC in the Northern Adriatic vary in a narrow range (Vojvodić and Ćosović, 1996) within a factor of two while SA variations 
vary within a factor of 15 one can conclude that the latter parameter is much more sensitive to changes in environmental conditions, such as changes in chemical and physical parameters and resulting biological responses.

The surface layer was the most variable part of the investigated region with respect to the SAS dynamics, which is clearly related to the temperature and freshwater pulses of the Po River as the dominant source of nutrients in the area (Degobbis, 1990).

\section{Acknowledgements}

The authors thank the scientific staff and the crew of the research vessel "Vila Velebita" for collecting the samples. The data on basic hydrography are obtained by courtesy of the Center for Marine Research in Rovinj, Ruđer Bošković Institute, Croatia. We thank Dr Robert Precali for making these data available to us. The authors wish to thank Dr Maurizio Pettine for valuable comments and improvement of the manuscript. Financial support provided from the Croatian Ministry of Science and Technology is gratefully acknowledged. 


\section{References}

Ahel, M., Terzić, S., 1998. Pigment signatures of phytoplankton dynamics in the northern Adriatic, Croat. Chem. Acta 71, 199-215.

Boicuort, W.C., Kuzmić, M., Hopkins, T.S., 1999. The inland sea: Circulation of Chesapeake Bay and the Northern Adriatic. In: Malone T.C., Malej, A., Harding, L.W., Smodlaka, N., Turner, R.E. (Eds.), Ecosystems at the land-sea margin : drainage basin to coastal sea. American Geophysical Union, Washington, DC, pp. 81-129.

Ćosović, B., 1985. Aqueous Surface Chemistry: Assessment of Adsorption Characteristics of Organic Solutes by Electrochemical Methods. In: Stumm, W. (Ed.), Chemical Processes in Lakes. Wiley, New York, pp. 55-80.

Ćosović, B., 1990. Adsorption kinetics of the complex mixture of organic solutes at model and natural phase boundaries. In Stumm, W. (Ed.), Aquatic chemical kinetics, Wiley, New York, pp. 291-310.

Ćosović, B., Vojvodić, V. (1982) The application of a.c. polarography to the determination of surface active substances in seawater. Limnol. Oceanogr. 27, 361-369.

Ćosović, B., Vojvodić, V. (1998) Voltammetric analysis of surface active substances in natural seawater. Electroanalysis 10, 429-434.

Degobbis, D., 1990. A stoichiometric model of nutrient cycling in the northern Adriatic Sea and its relation to regeneration processes. Mar. Chem. 29, 235-253.

Degobbis, D., Gilmartin, M., 1990. Nitrogen, phosphorus and biogenic silicon budgets for the Northern Adriatic sea. Oceanologica Acta 13, 31-45.

Degobbis, D., Fonda-Umani, S., Franco, P., Malej, A., Precali, R., Smodlaka, N., 1995. Changes in the northern Adriatic ecosystem and the hypertrophic appearance of gelatinous aggregates. Sci. Total Environ. 165, 43-58.

Frew, N.M., 1997. The role of organic films in air-sea gas exchange. In: Liss, P.S., Duce, R.A., (Eds.), The sea surface and global change. University Press, Cambridge, pp. 121172 .

Frew, N.M., Goldman, J.C., Dennett, M.R., Johnson, A.S., (1990) Impact of phytoplankton-generated surfactants on air sea gas exchange. J. Geophys. Res. 95, $3337-3352$ 
Gašparović, B., Ćosović, B., 1994. Electrochemical estimation of the dominant type of surface active substances in seawater samples using o-nitrophenol as a probe. Mar. Chem. 46, 179-188.

Gašparović, B., Ćosović, B., 1995. Electrochemical reduction of o-nitrophenol as a tool for the rough characterization of organic matter in seawater samples. Electroanalysis 7, 1136-1142.

Giani, M., Alberighi, L., Bacci, C., Boldrin, A., Puddu, A., Rabitti, S., 1999. A preliminary approach to carbon cycling in the Northern adriatic. European Community Ecosystems Research Report No 32: The Adriatic sea. 251-267.

Gilmartin, M., Kveder, S., Degobbis, D., Revelante, N., Smodlaka, N., 1972, Hydrographic data collected during cruises in the Northern Adriatic, July-December 1972. Thalassia Jugosl. 8, 149-213.

Gilmartin, M., Degobbis, D., Revelante, N., Smodlaka, N., 1990, The mechanism controlling plant nutrient concentrations in the northern Adriatic Sea. Int. Rev. Gesamten Hydrobiol. 75, 425-445.

Gilmartin, M., Revelante, N., 1991. Observations on particulate organic carbon and nitrogen concentrations in the northern Adriatic Sea. Thalassia Jugosl. 23, 39-49.

Harding, Jr. L.W., Degobbis, D., Precali, R., 1999. Production and fate of phytoplankton: Annual Cycles and Interanual Variability. In: Malone T.C., Malej, A., Harding, L.W., Smodlaka, N., Turner, R.E. (Eds.), Ecosystems at the land-sea margin : drainage basin to coastal sea. American Geophysical Union, Washington, DC, pp. 81-129.

Hunter, K.A., Liss, P.S., 1982. Organic sea surface films. In: Duursma, E.K., Dawson, R. (Eds.), Marine Organic Chemistry. Elsevier, Amsterdam, pp. 259-298.

Justić, D., Rabalais, N.N., Turner, R.E. Dortch, Q., 1995, Changes in nutrient structure of river-dominated coastal waters: Stoichiometric nutrients balance and its consequences. Estuarine Coastal Shelf Sci. 40, 339-356.

Kozarac, Z., Ćosović, B., Branica, M., 1976. Estimation of surfactant activity of polluted seawater by Kalousek commutator technique. J. Electroanal. Chem. 68, 75-83.

Kozarac, Z., Ćosović, B., Vojvodić, V., 1986. Electrochemical studies of the interaction of cadmium(II) with surface active material in natural and polluted waters, Water Res. 20, 295-300. 
Lee, C., Wakeham, S.G., 1988. Organic matter in seawater: biogeochemical processes. In: J.P. Riley (Ed.), Chemical Oceanography, Vol 9. Academic Press, San Diego, CA, pp. $1-49$.

Meyers-Schulte, K.J. and Hedges, JI., 1986, Molecular evidence for a terrestrial component of organic matter dissolved in ocean water. Nature, 321, 61-63.

Mozetič, P., Fonda Umani, S., Cataletto, B. Malej, A., 1998. Seasonal and inter-annual plankton variability in the Gulf of Trieste (northern Adriatic). J. Marine Sci. 55, 711722.

Pettine, M., Patrolecco, L., Camusso, M., Crescenzio, S., 1998. Transport of carbon and nitrogen to the northern Adriatic Sea by the Po River. Estuarine Coastal Shelf Sci. 46, 127-142.

Pettine, M., Patrolecco, L., Manganelli, M., Capri, S., Farrace, M.G., 1999. Seasonal variations of dissolved organic matter in the northern Adriatic sea. Mar. Chem. 64, 153-169.

Revelante, N., Gilmartin, M., 1976a. The effect of Po river discharge on phytoplankton dynamics in the Northern Adriatic sea. Mar. Biol. 34, 259-271.

Revelante, N., Gilmartin, M., 1976b. Temporal succession of phytoplankton in the northern Adriatic. Neth. J. Sea Res. 10, 377-396.

Vojvodić, V., Ćosović, B. Mirić, V., 1994. Fractionation of surface active substances on the XAD-8 resin. Part I. Mixtures of model substances. Anal. Chim. Acta. 295, 73-83.

Vojvodić, V., Ćosović, B., 1996. Fractionation of surface active substances on XAD-8 resin: Adriatic Sea samples and phytoplankton culture media. Mar. Chem. 54, 119133.

Žutić, V., Ćosović, B., Marčenko, E., Bihari, N., Kršinić, F., 1981. Surfactant production by marine phytoplankton. Mar. Chem. 10, 505-520.

\section{Figure captions:}

Fig. 1. Map of sampling stations in the North Adriatic Sea. 
Fig. 2. A.c. voltammograms of ONP probe for the seawater sample from the station 101, $0.5 \mathrm{~m}$ depth, taken in August 1999. Accumulation times: 0, 1, 3 and $10 \mathrm{~min}$ for the curves $1,2,3$ and 4, respectively.

Fig. 3. Calibration curve for the nonionic detergent Triton-X-100: dependence of the ONP peak potential shift on the increasing concentration of T-X-100. Accumulation time $3 \mathrm{~min}$.

Fig. 4. Salinity and temperature variations for the station 101 (Fig. 4a) and the station 107 (Fig. 4b), for the period from February 1998 to January 2000. Depths-Station 101: surface water $(\boldsymbol{\square}), 5 \mathrm{~m}(\nabla), 10 \mathrm{~m}(\boldsymbol{\nabla}), 20 \mathrm{~m}(\odot)$ and bottom water $(\bullet)$. Depths-Station 107: surface water $(\square), 5 \mathrm{~m}(\boldsymbol{\square}), 10 \mathrm{~m}(\nabla), 20 \mathrm{~m}(\boldsymbol{\nabla}), 30 \mathrm{~m}(\odot)$ and bottom water $(\bullet)$.

Fig. 5. Surfactant activity variations for the station 101 . The symbols denote measurement points, connected with lines (dotted lines) and fitted with sine function (full lines).

Fig. 6. Surfactant activity variations for the Station 107. Symbols denote measurement points, connected with lines (dotted lines) and fitted with sine function (solid lines).

Fig. 7. Surfactant activity of the surface layer $(0.5 \mathrm{~m})$ along the transect from the Po River mouth to Rovinj for the year 1998: May (curve 1), July (curve 2) and December (curve 3); and for the year 1999: February (curve 1), April (curve 2), May (curve 3) and August (curve 4).

Fig. 8. Distribution of salinity and temperature values for the surface layer $(0.5 \mathrm{~m})$ for all stations, for May (curve 1), July (curve 2) and December 1998 (curve 3).

Fig. 9. Distribution of salinity and temperature values for the surface layer $(0.5 \mathrm{~m})$ for the stations along the transect River Po-Rovinj, for February (curve 1), April (curve 2), May (curve 3) and August 1999 (curve 4). 


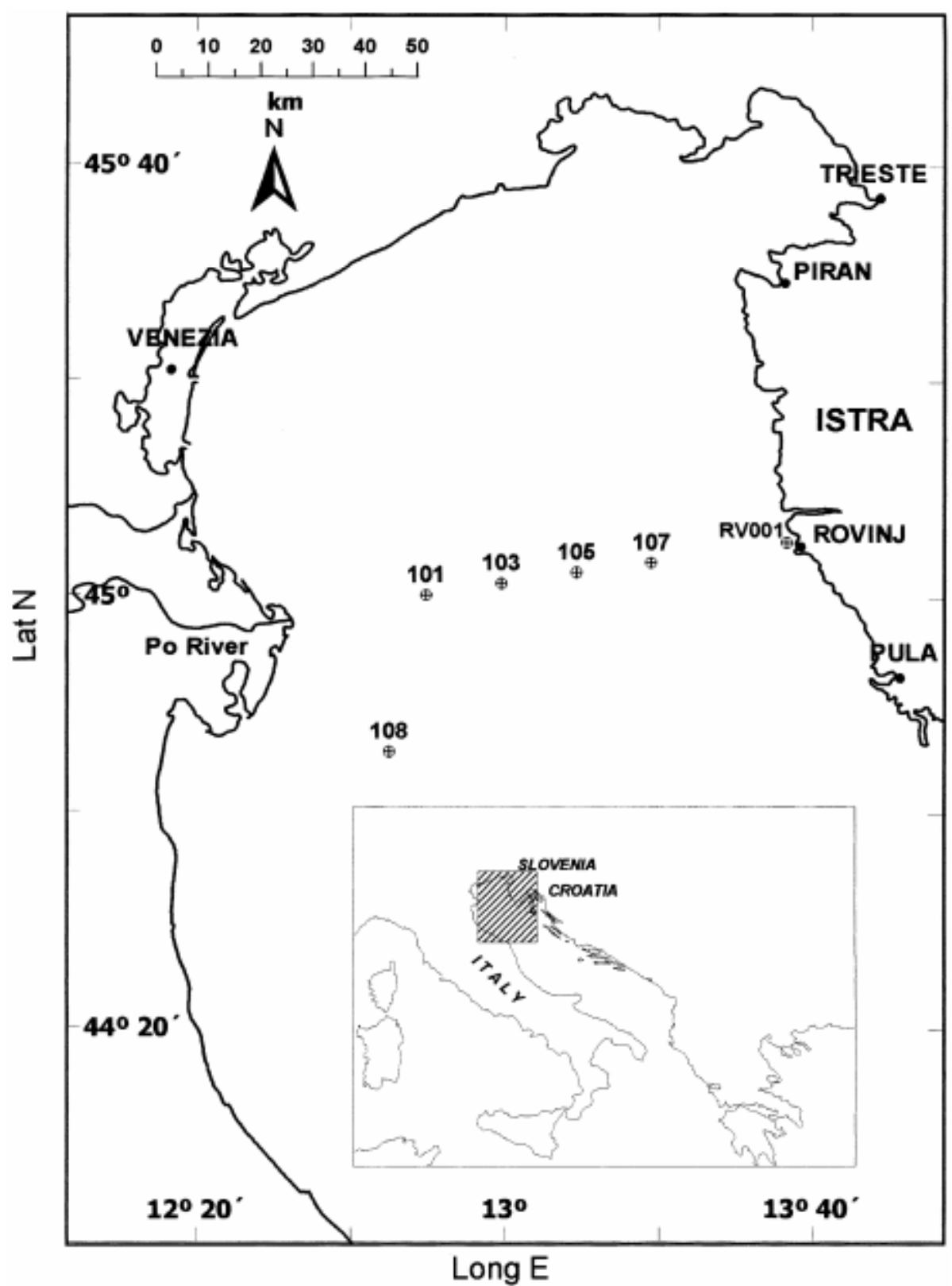

Fig. 1. Map of sampling stations in the North Adriatic Sea. 


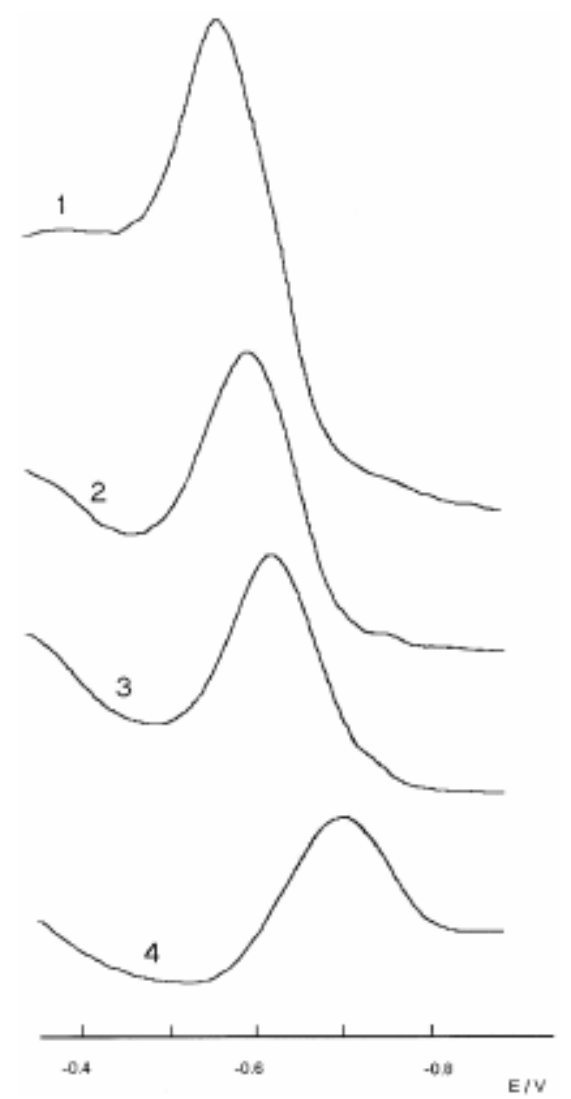

Fig. 2. A.c. voltammograms of ONP probe for the seawater sample from station 101, $0.5 \mathrm{~m}$ depth, taken in August 1999. Accumulation times: $0,1,3$ and 10 min for the curves $1,2,3$ and 4 , respectively.

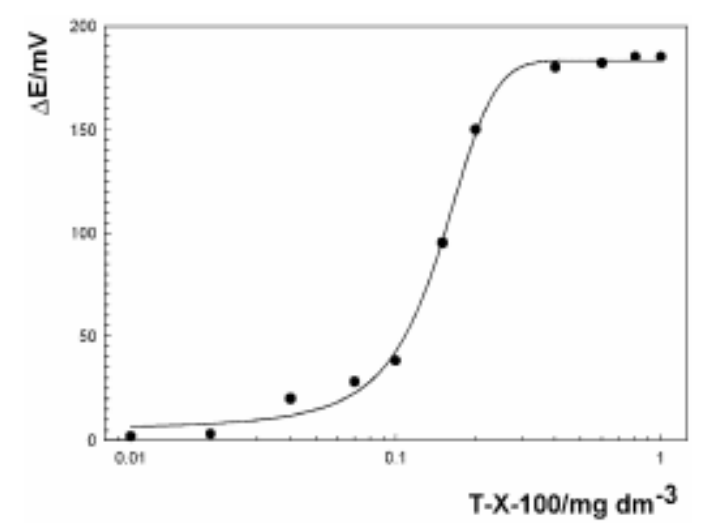

Fig. 3. Calibration curve for the nonionic detergent Triton-X-100: dependence of the ONP peak potential shift on the increasing concentration of T-X-100. Accumulation time $3 \mathrm{~min}$. 
(a)

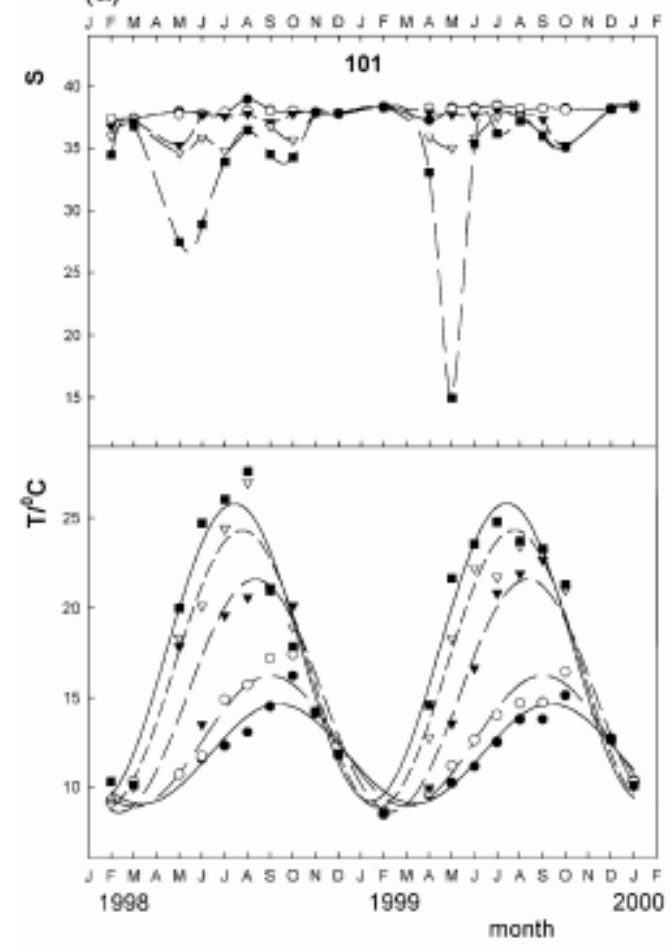

(b)

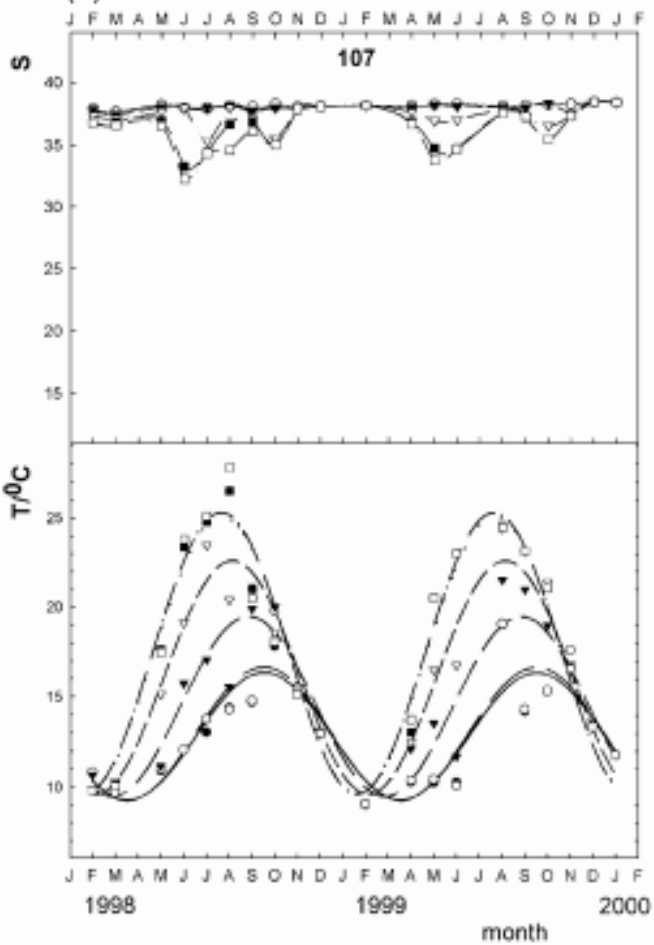

Fig. 4. Salinity and temperature variations for the station 101 (a) and the station 107 (b), for the period from February 1998 to January 2000 . Depths-Station 101: surface water $(\mathbf{v}), 5 \mathrm{~m}(\nabla), 10 \mathrm{~m}(\boldsymbol{\nabla}), 20 \mathrm{~m}(O)$ and bottom water $(\boldsymbol{O})$. Depths-Station 107: surface water $(\square), 5$ $\mathrm{m}(\mathbf{v}), 10 \mathrm{~m}(\nabla), 20 \mathrm{~m}(\mathbf{v}), 30 \mathrm{~m}(\mathrm{O})$ and bottom water $(\boldsymbol{\odot})$. 


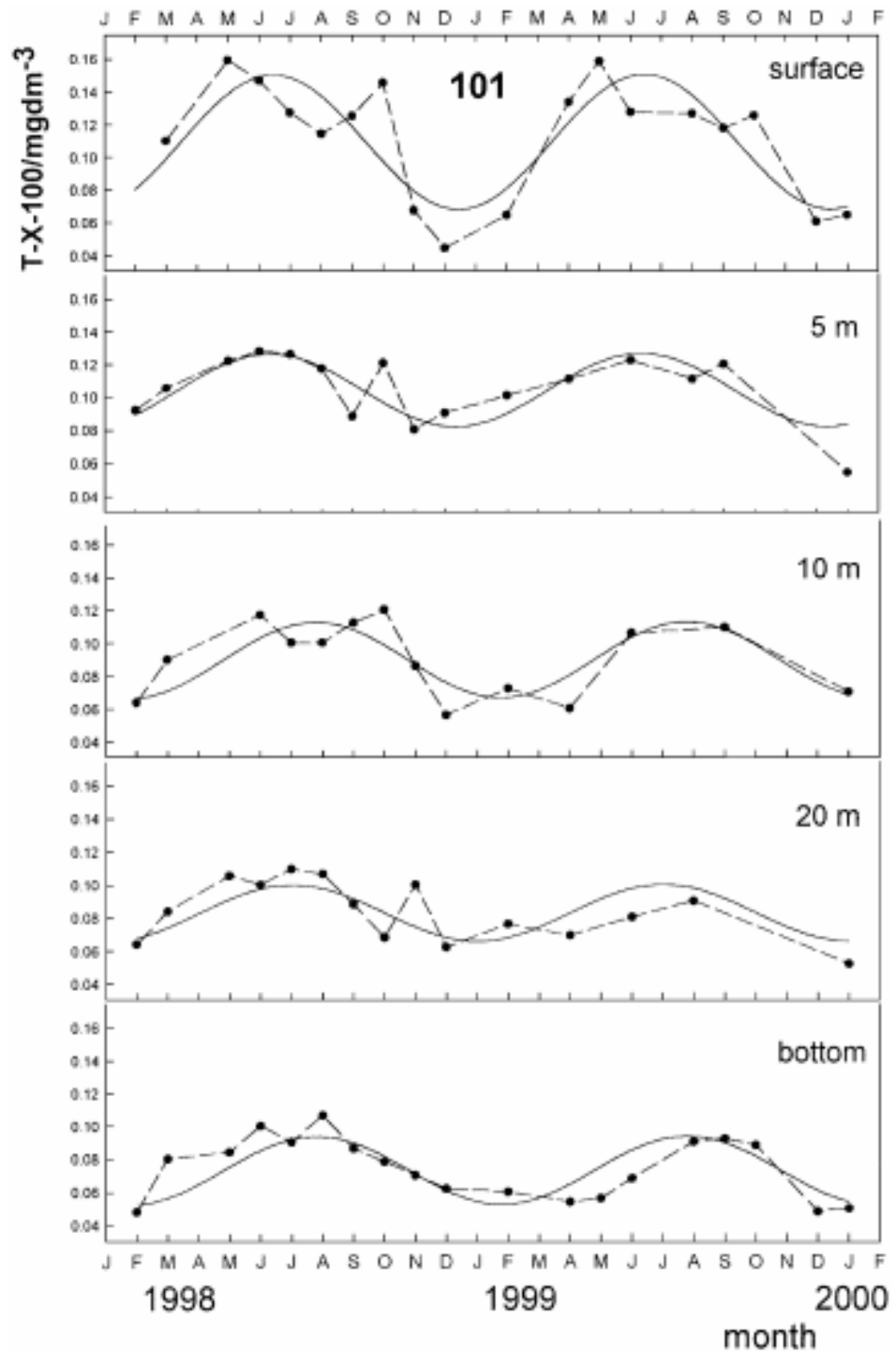

Fig. 5. Surfactant activity variations for the station 101. The symbols denote measurement points, connected with lines (dotted lines) and fitted with sine function (full lines). 


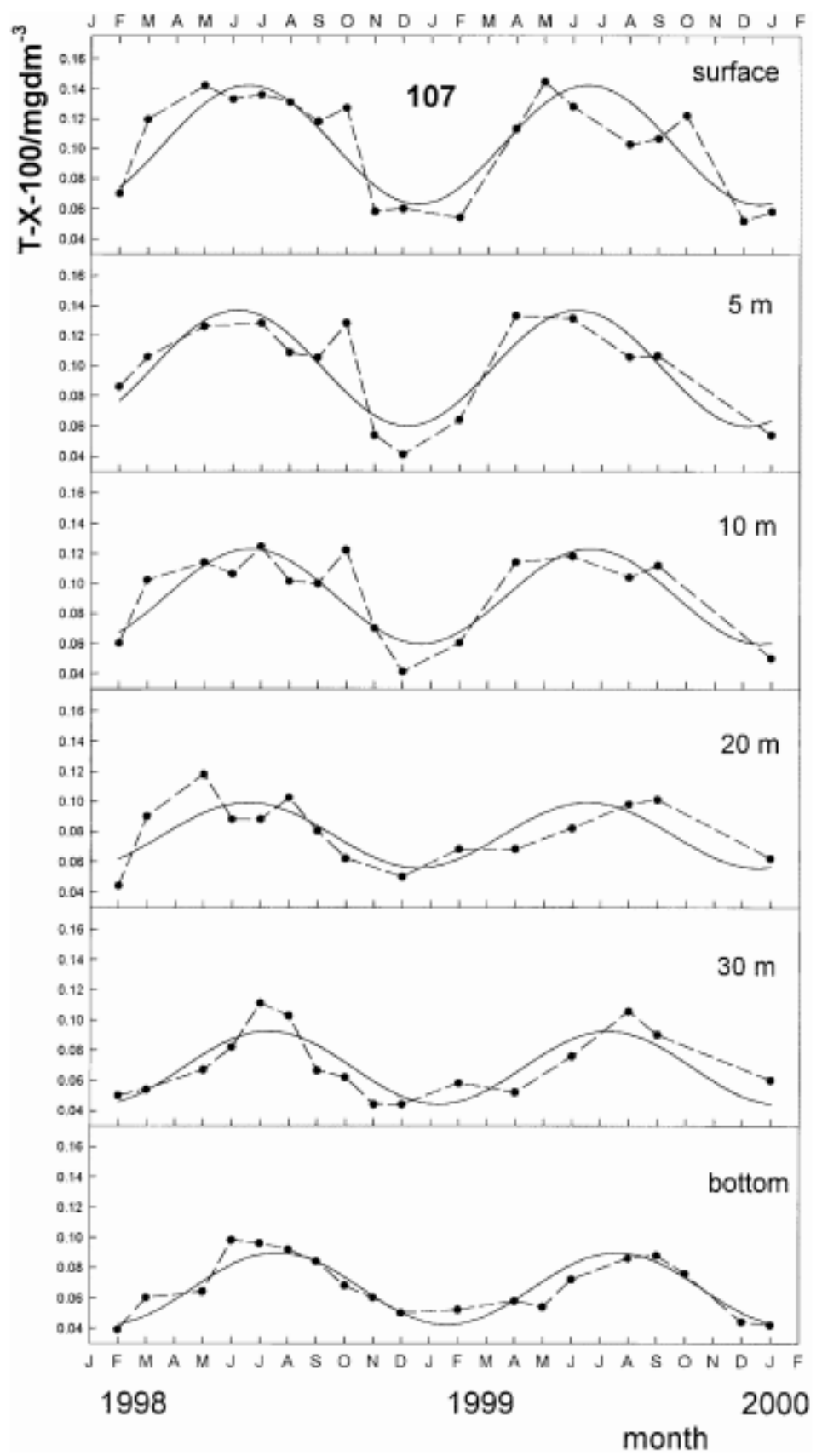

Fig. 6. Surfactant activity variations for the station 107. Symbols denote measurement points, connected with lines (dotted lines) and fitted with sine function (solid lines). 


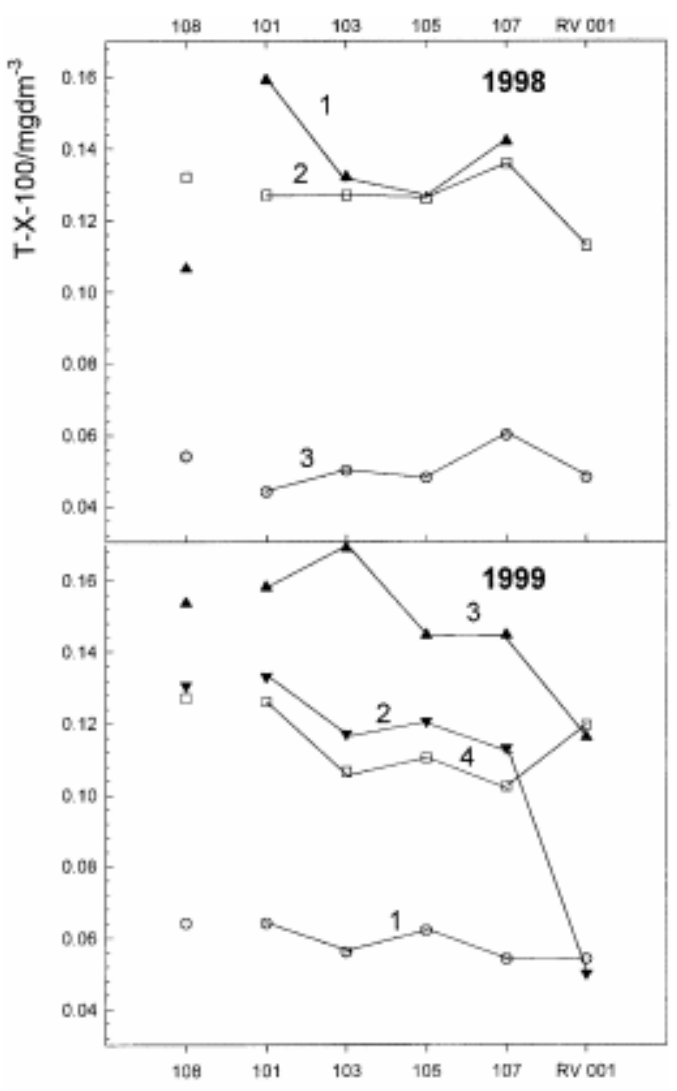

station

Fig. 7. Surfactant activity of the surface layer $(0.5 \mathrm{~m})$ along the transect from the Po River mouth to Rovinj for the year 1998: May (curve 1), July (curve 2) and December (curve 3); and for the year 1999: February (curve 1), April (curve 2), May (curve 3) and August (curve 4). 


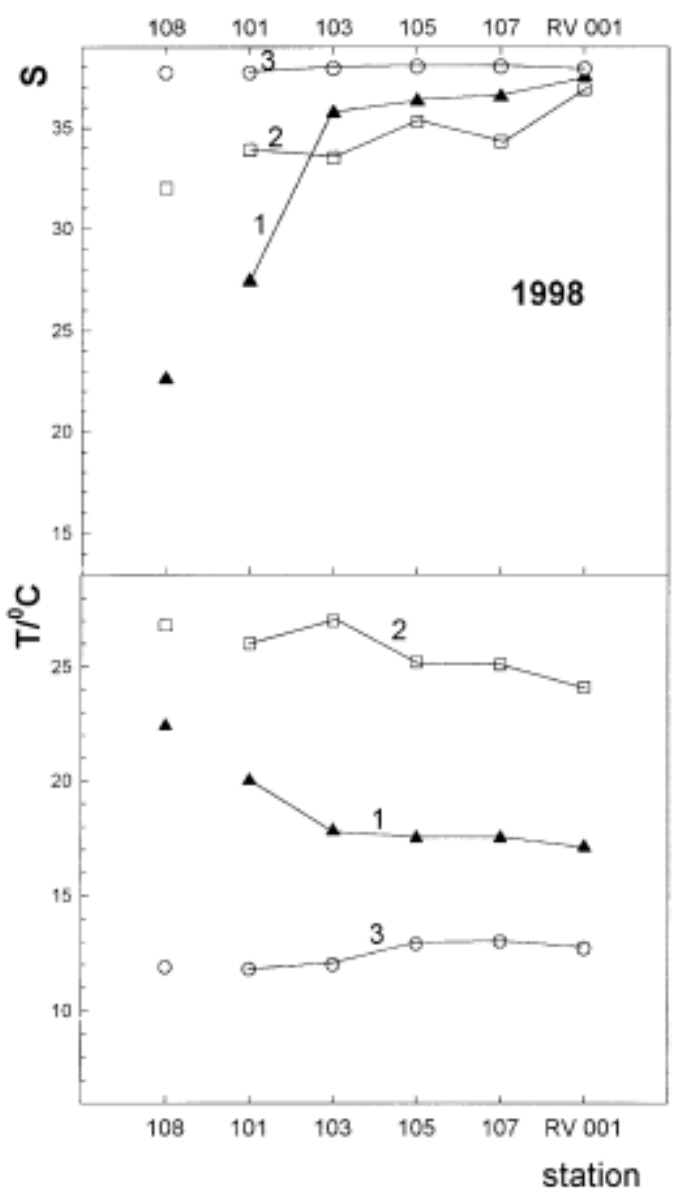

Fig. 8. Distribution of salinity and temperature values for the surface layer $(0.5 \mathrm{~m})$ for all stations, for May (curve 1), July (curve 2) and December 1998 (curve 3). 


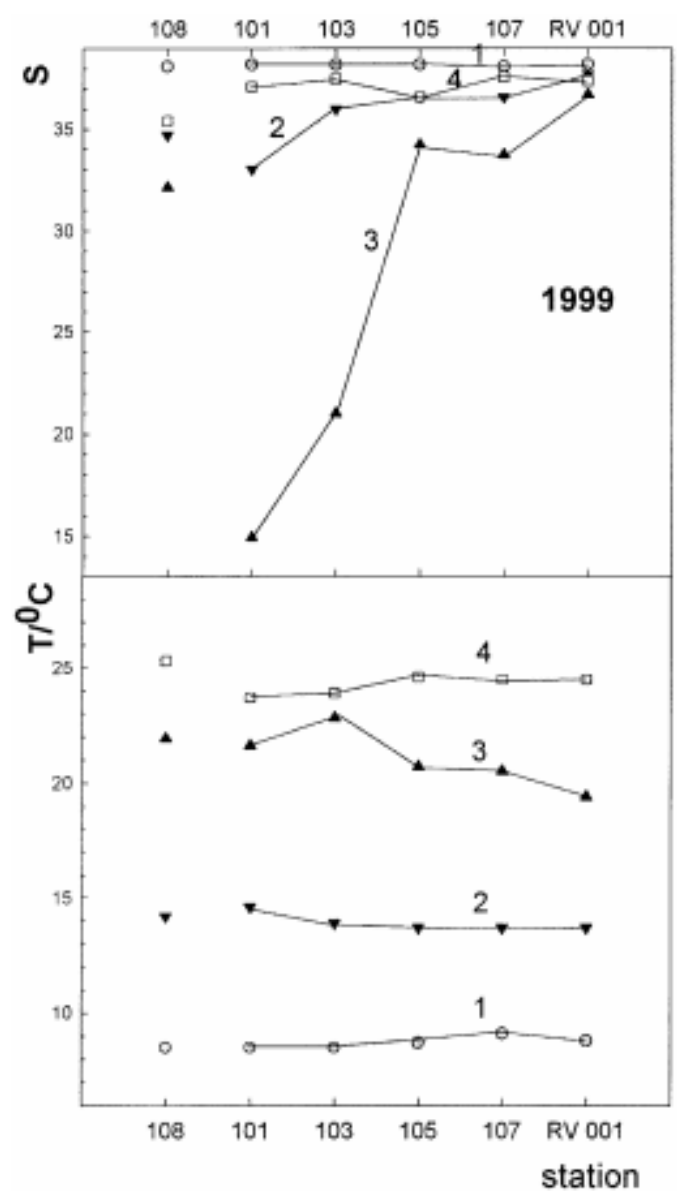

Fig. 9. Distribution of salinity and temperature values for the surface layer $(0.5 \mathrm{~m})$ for the stations along the transect River Po-Rovinj, for February (curve 1), April (curve 2), May (curve 3) and August 1999 (curve 4). 